\title{
Preparation, Biological Evaluation and Dosimetry Studies of 175Yb-Bis-Phosphonates for Palliative Treatment of Bone Pain
}

\author{
Kemik Ağrısının Palyatif Tedavisinde 175Yb-Bifosfonatların Hazırlanması, Biyolojik \\ Değerlendirmesi ve Dozimetre Çalışmaları
}

\author{
Ashraf Fakhari1, Amir R. Jalilian², Hassan Yousefnia², Saeed Shanehsazzadeh², Ali Bahrami-Samani2, Fariba Johari-Daha², \\ Mehdi Shafiee-Ardestani' ${ }^{\text {, Ali Khalaj1 }}$ \\ ITehran University of Medical Sciences, Faculty of Pharmacy, Tehran, Iran \\ 2Nuclear Science and Technology Research Institute (NSTRI), Tehran, Iran
}

\begin{abstract}
Objective: Optimized production and quality control of ytterbium-175 (Yb-175) labeled pamidronate and alendronate complexes as efficient agents for bone pain palliation has been presented.

Methods: Yb-175 labeled pamidronate and alendronate (175Yb-PMD and ${ }^{175} \mathrm{Yb}-\mathrm{ALN}$ ) complexes were prepared successfully at optimized conditions with acceptable radiochemical purity, stability and significant hydroxyapatite absorption. The biodistribution of complexes were evaluated up to $48 \mathrm{~h}$, which demonstrated significant bone uptake ratios for $175 \mathrm{Yb}-\mathrm{PAM}$ at all-time intervals. It was also detected that $175 \mathrm{Yb}-\mathrm{PAM}$ mostly washed out and excreted through the kidneys.

Results: The performance of $175 \mathrm{Yb}-\mathrm{PAM}$ in an animal model was better or comparable to other $175 \mathrm{Yb}$-bone seeking complexes previously reported.

Conclusion: Based on calculations, the total body dose for ${ }^{175} \mathrm{Yb}-\mathrm{ALN}$ is $40 \%$ higher as compared to $175 \mathrm{Yb}-\mathrm{PAM}$ (especially kidneys) indicating that ${ }^{175} \mathrm{Yb}-\mathrm{PAM}$ is probably a safer agent than ${ }^{175} \mathrm{Yb}-\mathrm{ALN}$.

Keywords: Yb-175, pamidronic acid, alendronic acid, bone pain palliation therapy, biodistribution, dosimetry
\end{abstract}

\section{Öz}

Amaç: iterbiyum-175 (ib-175) işaretli pamidronat ve alendronat komplekslerinin kemik ağrısı palyasyonu için etkin ajanlar olarak optimal üretim ve kalite kontrolü sunulmaktadır.

Yöntem: ib-175 işaretli pamidronat ve alendronat (175ib-PMD ve ${ }^{175} \mathrm{ib}-\mathrm{ALN}$ ) kompleksleri kabul edilebilir radyokimyasal saflık, stabilite ve anlamlı hidroksiapatit emilimi ile optimize koşullarda başarılla hazırlandı. Komplekslerin biyodağılımı 48 saate kadar değerlendirildi ve tüm zaman aralıklarında 175ib-PAM ile anlamlı kemik tutulum oranı saptandı. Aynı zamanda 175ib-ALN'nin çoğunlukla böbrekler yoluyla ekskrete edildiği tespit edildi.

Bulgular: Bir hayvan modelinde, 175ib-PAM'ın performansı daha önce bildirilen diğer 175ib-kemiğe bağlanan kompleksler ile eşit ya da daha iyi olarak bulundu.

Sonuç: Hesaplamalara göre, ${ }^{175} \mid \mathrm{ib}-A L N$ 'nin için toplam vücut dozu (Özellikle böbreklerde) ${ }^{175}{ }^{1} \mathrm{~b}-\mathrm{PAM}$ 'dan \%40 daha yüksektir. Bu durum, $175 \mathrm{ib}-\mathrm{PAM}$ 'in ${ }^{175} \mathrm{ib}-\mathrm{ALN}$ 'den daha güvenli bir alternatif olduğunu öne sürmektedir.

Anahtar kelimeler: ỉb-175, pamidronik asit, alendronik asit, kemik ağrısı palyatif tedavisi, biodağılım, dozimetre

Address for Correspondence: Amir R. Jalilian MD, Nuclear Science and Technology Research Institute (NSTRI), Tehran, Iran Phone: +98-21-88221103 E-mail: ajalili@aeoi.org.ir Received: 20.04.2015 Accepted: 20.07.2015 


\section{Introduction}

The incidence of bone metastasis is increasing mostly due to breast or prostate cancer, in other words primary bone cancer is becoming rare. Most of these patients suffer from severe pain that cannot be relieved by pharmaceuticals. Radiotherapy is an effective method for the treatment of tumor regions. However, in metastatic bone disease, the damaged regions are scattered, making radiotherapy an undesirable option. In most patients, chemotherapy is used in order to prevent malignant cell proliferation and cause cell death if the illness is in initial stages. In some cases, radiopharmaceuticals are valid choices for treatment (1). Beta emitters have already been used for the treatment and palliation of many types of cancer, particularly metastatic bone disease. For this purpose, an appropriate molecule that is absorbed into the bone as a ligand is labeled with a beta emitter radioisotope. The applied ligand can be a known drug or a new structure that can be absorbed into the bone. Many tetraphosphonates and bisphosphonates are being used for this purpose based on absorption of the phosphate group into the bone. When choosing radioisotopes, many features including the half-life, range and energy of beta particles should be taken into account. Numerous phosphonates were labeled with suitable radio lanthanide beta emitters and were used in clinical nuclear medicine for either therapy or palliation, due to the incidence of bone metastases in the world. For instance, preparation and application of $153 \mathrm{Sm}$-EDTMP (2) as a tetraphosponate and $166 \mathrm{Ho}$ bisphosphonate is more outstanding (3). Bisphosphonates, a class of drugs that prevent loss of bony mass, are used to treat osteoporosis and similar diseases. Bone undergoes constant turnover and is kept in a balance (homeostasis) of osteoblasts creating bone and osteoclasts destroying bone. Bisphosphonates inhibit bone digestion by encouraging osteoclasts to undergo apoptosis, or cell death, thereby slowing bone loss. The two $\mathrm{PO}_{3}$ (phosphonate) groups that are covalently linked to carbon determine both the name "bisphosphonate" and the function of the drugs. Because of the importance of bisphosphonates among other bone pharmaceuticals, many agents within this class such as alendronate, pamidronate, etidronate, and zoledronic acid have been labelled with therapeutic radioisotopes such as $153 \mathrm{Sm}, 166 \mathrm{Ho}, 186 \mathrm{Re}$ or diagnostic radioisotopes and have been used in clinical practice so far.

$175 \mathrm{Yb}$ can be produced by thermal neutron bombardment of natural ytterbium target. The simplified production scheme is: ${ }^{174} \mathrm{Yb}(\mathrm{n}, \gamma){ }^{175} \mathrm{Yb} \rightarrow{ }^{175} \mathrm{Lu}$ (Stable) $\sigma=69$ barn (Table 1) (4).

$175 \mathrm{Yb}(\mathrm{T} 1 / 2=4.185 \mathrm{~d})$ is an interesting radionuclide for targeted therapy modalities. Absorbed radiopharmaceutical remains in bone and acts as an internal generator. The beta energy is suitable that decay in bone without bone marrow separation (5).
The idea of developing bone avid agents based on ligands draws attraction due to the inhibitory binding affinity constant (Ki) of bisphosphonates used in clinical practice including pamidronate $(83 \mu \mathrm{M})$ and alendronate $(82 \mu \mathrm{M})$. In one study with $177 \mathrm{Lu}$-zoledronate, the resulting complex was not stable in vivo as compared to other therapeutic bisphosphonates due to the existence of an imidazole ring (6). Thus, other ligands of interest based on their affinity constants and if they contain aliphatic amino chains were considered, such as pamidronic acid and alendronic acid.

In this study, the $175 \mathrm{Yb}$-alendronate and $175 \mathrm{Yb}$ pamidronate complexes were prepared followed by preclinical evaluation including in vitro/vivo stability, and biodistribution studies by post-mortem studies. In continuation with previous experiences in the estimation of effective human dose extrapolation from rodents' data $(7,8,9)$, we attempted to compare the biodistribution data of intravenous (iv) injection of $175 \mathrm{Yb}$-Alendronate $(175 \mathrm{Yb}$ ALN) and 175Yb-Pamidronate (175Yb-PAM), as well as a prediction of the human absorbed dose of each tracer that is derived from rat data (Figure 1).

\section{Materials and Methods}

The natural ytterbium oxide was purchased from Isotec Inc, USA and ${ }^{175} \mathrm{Yb}$ was produced in the Tehran Research Reactor (TRR). Whatman No. 2 was obtained from Whatman (Maidstone, UK). Radio-chromatography was performed by using a Bioscan AR-2000 radio TLC scanner instrument (Bioscan, Paris, France). All other chemical reagents were purchased from Merck (Darmstadt, Germany). An approval was obtained from the Nuclear Science and Technology Research Institute Ethics Committee to conduct this research study. The Sprague Dawley rats were purchased from Pasteur Institute of Iran, Karaj, all weighed 20-25 $\mathrm{g}$, were acclimatized at proper rodent diet and kept at $12 \mathrm{~h} / 12 \mathrm{~h}$ day/night light/darkness.

\section{Table 1. Beta decay characteristics for Yb-175 radionuclide}

\begin{tabular}{ll}
\hline Abundance (\%) & Maximum energy of beta (keV) \\
\hline 10.2 & 73.67 \\
3.3 & 356.2 \\
86.5 & 470
\end{tabular}
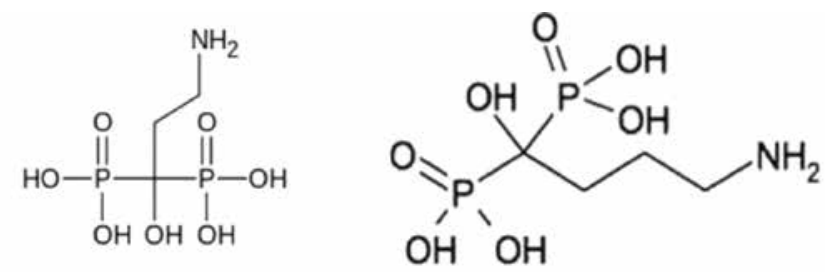

Figure 1. Chemical structure for pamidronic acid (left) and alendronic acid (right) 
Production and Quality Control of $175 \mathrm{YbCl}_{3}$ Solution Ytterbium-175 was produced by neutron irradiation of $1 \mathrm{mg}$ of natural $\mathrm{Yb}_{2} \mathrm{O}_{3}$ at the neutron flux of $3 \times 10^{13} \mathrm{n} /$ $\mathrm{cm}^{2} / \mathrm{s}$. Irradiation was carried out for $7 \mathrm{~d}$. The irradiated target was dissolved in $0.1 \mathrm{M} \mathrm{HCl}$ and the resultant solution was evaporated and was reconstituted in double distilled water. The radionuclidic purity of the solution was checked by using both high purity germanium (HPGe) spectroscopy for the detection of various interfering gamma emitting radionuclides and beta scintillation tests. Gamma spectroscopy of the final sample was carried out counting in an HPGe detector coupled to a Canberra TM multi-channel analyzer for $1000 \mathrm{~s}$. The radiochemical purity of the $175 \mathrm{YbCl}_{3}$ was checked using two solvent systems by ITLC on Whatman No. 2 papers. A: $10 \% \mathrm{NH}_{4} \mathrm{OAc}$ and methanol (1:1) and $B: 10$ mM DTPA solution (pH 5).

Radiolabeling of Bisphosphonates with ${ }^{175} \mathrm{YbCl}_{3}$

Stock solutions of mono sodium bisphosphonates salt were prepared by dissolution double distilled ultra pure water, to produce a solution of $50 \mathrm{mg} \mathrm{mL}^{-1}$ separately. For labeling, an appropriate amount of the ${ }^{175} \mathrm{YbCl}_{3}$ solution containing the required activity $(0.1 \mathrm{~mL}, 1850 \mathrm{MBq})$ was added to the desired amount of stock solutions (0.3 $\mathrm{mL}, 1: 5 ; 1: 10 ; 1: 15 ; 1: 20 ; 1: 40$ and 1:50 ratios for $\mathrm{Yb}$ : bisphosphonate). The $\mathrm{pH}$ of the mixtures was adjusted to 7. The complex solutions were kept at room temperature for 60-360 min. In addition, another set of experiment was performed at $60{ }^{\circ} \mathrm{C}$ warm bath for $60-360 \mathrm{~min}$. The radiochemical purity was determined using ITLC. The final solution was passed through a $0.22-\mu \mathrm{m}$ membrane filter and $\mathrm{p} \mathrm{H}$ was adjusted to $7-8.5$ with $0.05 \mathrm{molL}^{-1}$ phosphate buffer (pH 5.5). A $5 \mathrm{~mL}$ sample of the final fraction was spotted on a chromatography Whatman No. 3 paper, and developed in Whatman $3 \mathrm{MM}$ chromatography paper or ITLC-SG eluted with $\mathrm{NH}_{4} \mathrm{OH}$ (56\%): $\mathrm{MeOH}(100 \%): \mathrm{H}_{2} \mathrm{O}$ $(100 \%)(0.2: 2: 4 ; v / v / v)$ as mobile phase mixture. Sterility was controlled with a random sampling following decay of radioactivity. The Limulus amoebocyte lysate (LAL) test was used for validation of radiopharmaceutical production according to the European protocol (10).

Stability of $175 \mathrm{Yb}$-Bisphosphonates in Final Formulation

Stability of $175 \mathrm{Yb}$-bisphosphonates in the final preparation was determined by storing the final solution at $25^{\circ} \mathrm{C}$ for up to $48 \mathrm{~h}$ and performing frequent ITLC analysis to determine radiochemical purity using Whatman $3 \mathrm{MM}$ chromatography paper or ITLC-SG eluted with $\mathrm{NH}_{4} \mathrm{OH}$ (56\%): $\mathrm{MeOH}(100 \%): \mathrm{H}_{2} \mathrm{O}$ (100\%) (0.2:2:4; v/v/v).

In Vitro Protein Binding of $175 \mathrm{Yb}-B i s p h o s p h o n a t e s$ in the Presence of Human Serum

In vitro protein binding of $175 \mathrm{Yb}$-bisphosphonates was carried out in human blood by protein precipitation according to the published procedure (11). Three $\mathrm{mL}$ fresh human plasma was mixed with $1 \mathrm{~mL}$ of the labeled complex, and incubated for $1 \mathrm{~h}$ at $37{ }^{\circ} \mathrm{C}$. Contents of the tube were centrifuged at $3000 \mathrm{rpm}$ for $10 \mathrm{~min}$ for separation of serum and blood cells. After adding approximately equal volume of $10 \%$ trichloroacetic acid (TCA), the mixture was centrifuged at $3000 \mathrm{rpm}$ for another $10 \mathrm{~min}$. The residue was separated from the supernatant and both layers were counted for radioactivity in a well type gamma counter. Protein binding of the complex was expressed as the fraction of radioactivity bound to protein, as percentage of the total radioactivity.

In Vitro Stability of $175 \mathrm{Yb}$-Bisphosphonates in the Presence of Human Serum

The final solution $(200 \mu \mathrm{Ci}, 50 \mu \mathrm{L})$ was incubated in the presence of freshly prepared human serum $(300 \mu \mathrm{L})$ (Purchased from Iranian Blood Transfusion Organization, Tehran) and kept at $37{ }^{\circ} \mathrm{C}$ for 2 days. Trichloroacetic acid $(10 \%, 100 \mu \mathrm{l})$ was added every $30 \mathrm{~min}$ to a portion of the mixture $(50 \mathrm{~mL})$, and the mixture was centrifuged at 3000 rpm for 5 min followed by decanting the supernatant from the debris. The stability was determined by performing frequent ITLC analysis of the supernatant by using the aforementioned ITLC system.

\section{Hydroxyapatite Binding Assay}

The hydroxyapatite binding assay was performed according to the previously described procedure (12), with only a slight modification. In summary, $2 \mathrm{~mL}$ of saline solution of $\mathrm{pH} 7.4$ were added to vials containing 1.0, 2.0, 5.0, 10.0, 20.0 and $50.0 \mathrm{mg}$ of solid hydroxyapatite, and the mixtures were shaken for $1 \mathrm{~h}$. Then, $50 \mathrm{~mL}$ of the radioactive preparation was added and the mixtures were shaken for $24 \mathrm{~h}$ at room temperature. The suspensions were centrifuged, and two aliquots of the supernatant liquid were taken from each vial and radioactivity was measured with a well-type counter. Test experiments were performed using a similar procedure, this time in the absence of hydroxyapatite. The binding percentage of ${ }^{175} \mathrm{Yb}$ to hydroxyapatite (HA) was calculated according to $H B=1-A / B \times 100$, where $A$ is the mean radioactivity value of the supernatant sample being studied and $B$ is the mean total value of whole activity used.

\section{Biodistribution in Sprague Dawley ${ }^{\circledR}$ Rats}

During the entire study, autoclaved food and drinking water were available ad libitum. Animal studies were carried out in accordance with the UK Biological Council's Guidelines on the Use of Living Animals in Scientific Investigations, 2nd edition (approved by Iranian Ministry of Health and Medical Education) (11). To determine its biodistribution, the radiotracer was administered to Sprague Dawley ${ }^{\circledR}$ rats that were purchased from Razi Institute, Karaj, Iran. One hundred $\mu \mathrm{L}$ of final radiotracer solution containing 7-7.4 MBq radioactivity was injected intravenously to rats through their tail vein. The total amount of radioactivity injected into each animal was measured by counting the 1 - $\mathrm{ml}$ syringe before and after injection in a dose calibrator with fixed geometry. The animals were sacrificed using the animal care protocols at selected times after injection (2 to $48 \mathrm{~h}$ ), the tissues (blood, heart, lung, small intestine, large intestine, skin, stomach, kidneys, liver, muscle and bone) were removed, washed with normal saline and 
dried in paper toweling (12). Each sample was weighed and counted with an HPGe detector 3 times, along with standards prepared from a sample of the injected material. The percentage of injected dose per gram (ID/g \%) of each organ was measured by direct counting from 11 harvested rat organs (based on the area under $396.33 \mathrm{keV}$ peak obtained by an HPGe detector).

\section{Measurement of Activity}

All samples were background subtracted, the decay correction was not performed, and similar samples were averaged together. For each of these measurements, three samples (from each organ) were weighed and then counted by HPGe to determine the percentage of injected dose per gram (which was equivalent to the percentage of injected activity per gram $\% \mid \mathrm{A} / \mathrm{g} \equiv \% \mathrm{ID} / \mathrm{g}$ ); all the organ activity measurements were normalized to injected activity (13). In all measurements, we tried to keep the same geometry and same volume in order to prevent overestimation and underestimation in dose measurements (14). Uncertainties in the determinations were minimal, because each assay collected at least 10,000 counts, which resulted in a standard deviation (SD) of less than 1\%. All samples were background subtracted and decay correction was not considered for all measurements, and the similar samples were averaged together. The activity in the syringes was measured before and after administration of the radiopharmaceutical with well-type ionization chamber (CRC-15R, Capintec, USA N.J.).

The HPGe detector provides us a count, therefore we used the below formula to convert these counts into activity measure (15):

(Eq.1)

Where $t$ is the time of counts and Eff is the efficiency of the detector for the selected energy and $\mathrm{Br}$ is the decay yield of selected energy (396.33 keV) for 175 Ytterbium.

The $175 \mathrm{Yb}$ activity concentration at time $\mathrm{t}, \% \mathrm{ID} / \mathrm{g}(\mathrm{t})$, was then calculated as the percentage of injected activity per gram of tissue $(\% \mid \mathrm{A} / \mathrm{g})$ :

(Eq.2)

Where $A_{\text {tissue }}$ is the ${ }^{175} \mathrm{Yb}$ activity in the sample, $\mathrm{M}_{\text {tissue }}$ is the mass of the sample and $A_{\text {total }}$ is the total activity of $175 \mathrm{Yb}$ injected into the rat $(15,16)$.

The cumulated activity in the source organs, can be calculated by equation 3 :

(Eq.3)

Where $A_{h}(t)$ is the activity of each organ at time $t$ (16). In this study, the accumulated source activity was calculated by plotting the non-decay corrected time activity curves for each organ and computing the area under the curves. For this purpose, the data points which represent the percentage-injected dose were created and fitted to a mono-exponential, bi-exponential or uptake and clearance curve (17). In addition, the curves were extrapolated to infinity ( 5 times higher than physical half-life of ${ }^{175} \mathrm{Yb}$ ) by fitting the tail of each curve to a mono-exponential curve. Then the area under the curve was calculated in the same way as explained in a previous study by our group on determination of the absorbed dose of 67Ga-DTPA-ACTH (18). In order to prevent under-sampling for the area under the curves (AUCs), we tried to calculate the AUCs when the R2 square of fitted curves were above 0.9 for each organ. We used the mentioned criteria, and included 11 organs for AUCs calculation as source organs for MIRD.

Extrapolation of the Organ Uptake Data to Humans

The organ uptake data in animals were used to extrapolate the equivalent uptake in humans by the proposed method of Sparks and Aydogan (19) as represented in equation 4.

\section{(Eq.4)}

\section{Absorbed Dose Calculations}

The absorbed radiation dose was calculated by MIRD formulation (19):

(Eq.5)

Where $D\left(r_{k}\right)$ is the absorbed dose of the target organ, is the accumulated activity in source organs, and called the $\mathrm{S}$ factor is defined as the mean absorbed dose to the target region $r_{k}$ per unit accumulated activity in the source region $r_{h}$. The $S$ factor represents the physical decay characteristics of radioisotopes, the range of emitted radiations, and the organ size and configuration expressed in ( $\mathrm{mSv} /\left(\mathrm{MBq}^{*} \mathrm{~s}\right)$ ) (20). The $S$ factors have been taken from the tables presented in the Medical Internal Radiation Dose No.11 also available in http://doseinfo-radar.com/RADARphan. html (20).

\section{Calculation of Effective Absorbed Dose}

The effective absorbed dose of each organ is calculated by the expression:

(Eq.6)

Where $\mathrm{H}_{\mathrm{T}}$ is the equivalent dose in a tissue or organ, while $T$ and $W_{T}$ represent the tissue-weighting factor according to ICRP 106 (21).

\section{Results}

\section{Production of ${ }^{175} \mathrm{Yb}$}

Around $1.5-2 \mathrm{GBq} / \mathrm{g}$ of $175 \mathrm{Yb}$ activity was obtained after 7 days of irradiation at a flux of $3 \times 10^{13} \mathrm{n} / \mathrm{cm}^{2} / \mathrm{s}$ using natural $\mathrm{Yb}_{2} \mathrm{O}_{3}$ target. $A$ thorough study on the various irradiation times and neutron fluxes was performed for radionuclide production to achieve an optimized condition determination. Major radionuclidic impurities in irradiated samples were shown to be. ${ }^{169} \mathrm{Yb}$ and ${ }^{177 \mathrm{Lu} \text { based on time }}$ of irradiation.

The observed gamma-photo peaks correspond to the gamma-photo peaks of $175 \mathrm{Yb}(113,144,286$ and 396 $\mathrm{keV}), 169 \mathrm{Yb}(63,110,130,177,198,261$ and $307 \mathrm{KeV})$ and $177 \mathrm{Lu}$ (208 and $250 \mathrm{keV}$ ). By analyzing the gamma-ray spectra, the radionuclidic purity of $175 \mathrm{Yb}$ was found to be $96.2 \%$ with the presence of $2.1 \% 169 \mathrm{Yb}$. Beta spectrum of the final sample used in radiolabeling was also obtained showing a maximum peak around channel 450. The calculated specific activity of Yb-175 was $600-800 \mathrm{GBq} /$ mmol (Figure 2). 
For radiochemical purity, two solvent systems were used. In a mixture of $10 \% \mathrm{NH}_{4} \mathrm{OAc}$ :methanol (1:1), the free cation remains at the base while any undistinguished anions would migrate to higher $R_{f} s$ (not observed). On the other hand in $10 \mathrm{mM}$ DTPAsolutionYb-175 cation is complexed in ${ }^{175} \mathrm{Yb}$-DTPA form migrating to higher $R_{f} S$ and any possible colloidal fraction would remain at the base (Figure 3).

The radiochemical purity in $10 \mathrm{mmol} \mathrm{L}^{-1}$ DTPA aq. solution (solvent 1), free ${ }^{175} \mathrm{Yb}^{3+}$ cation is complexed to more lipophilic $175 \mathrm{Yb}$-DTPA form and migrates to higher Rf. The small radioactive fraction remaining at the origin could be related to other $\mathrm{Yb}$ ionic species that do not form $\mathrm{Yb}$ DTPA complex, such as $\mathrm{YbCl}_{4}$ - and/or colloids. On the other hand, 10\% ammonium acetate:methanol mixture (1:1) (solvent 2) was used for determination of radiochemical purity. The fast eluting species was $\mathrm{Yb}^{3+}$. Other ionic forms of $175 \mathrm{Yb}$ such as $\mathrm{YbCl}_{4}{ }^{-}$as well as colloids remained at the origin $(R f=0)$ (Figure 4).

Labeling Optimization Studies: In order to obtain maximum complex yields, several experiments were carried out with different reaction parameters such as ligand concentration, $\mathrm{pH}$, reaction time and temperature.

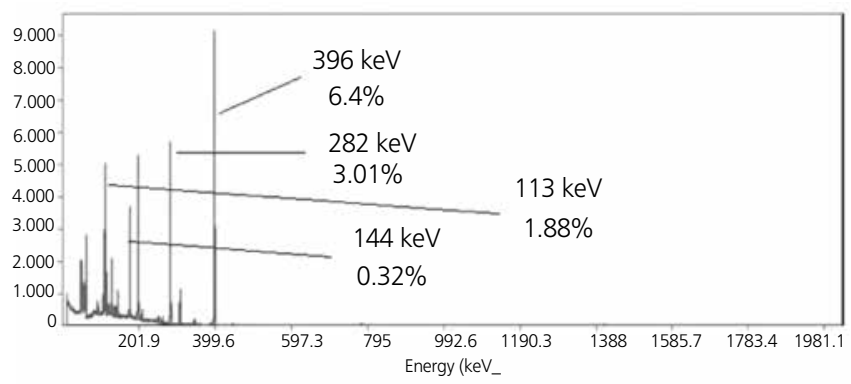

Figure 2. Gamma spectrum for ${ }^{175} \mathrm{YbCl}_{3}$ solution used in radiolabeling
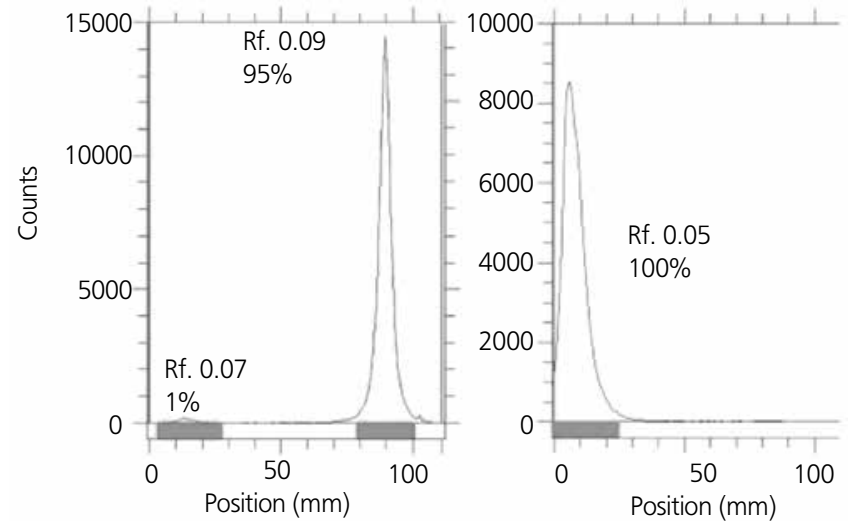

Figure 3. ITLC chromatograms of ${ }^{175} \mathrm{YbCl}_{3}$ solution in $10 \mathrm{mM}$ DTPA solution (pH 4) (left) and in 10\% ammonium acetate: methanol (1:1) (right) on Whatman No. 1 Paper
Ligand concentration varied between a wide range starting from 10 to $50 \mathrm{mg} / \mathrm{mL}$ for bisphosphonates. At optimum optimized conditions, $175 \mathrm{Yb}-\mathrm{ALN}$ was obtained with a specific activity of $3.7 \pm 0.2 \mathrm{GBq} / \mathrm{mmol}$ while it was $4.1 \pm 0.2$ $\mathrm{GBq} / \mathrm{mmol}$ for $175 \mathrm{Yb}-\mathrm{PAM}$.

It was observed that at room temperature $>95 \%$ complex was achieved with $15 \mathrm{mg} / \mathrm{mL}$ of bisphosphonates. The best ITLC mobile phase was evaluated by Whatman No.2 paper using $\mathrm{NH}_{4} \mathrm{OH}$ : $\mathrm{MeOH}: \mathrm{H}_{2} \mathrm{O}(0.2: 2: 4)$ as shown in Figure 5.

The effect of various factors such as ligand concentration and temperature on labeling yield of $166 \mathrm{Yb}-\mathrm{PMD}$ were also studied. The results are shown in Table 2. Labeling yield increased with increasing molar ratio Yb:PMD (from 1:5 to $1: 50$ ) and reached to more than $99 \%$ in 60 minutes (Table 1). The stability of prepared $175 \mathrm{Yb}$-complexes was checked up to 48 hours after preparation. The complex was stable in final pharmaceutical sample and its radiochemical purity was above $99 \%$ even 48 hours after preparation using Whatman $3 \mathrm{MM}$ eluted with $\mathrm{NH}_{4} \mathrm{OH}: \mathrm{MeOH}: \mathrm{H}_{2} \mathrm{O}(0.2: 2: 4)$.

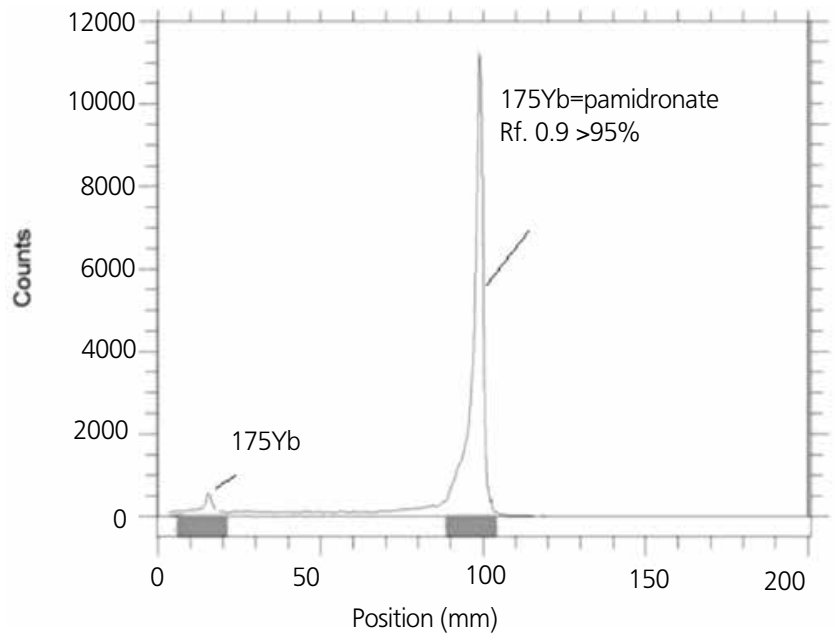

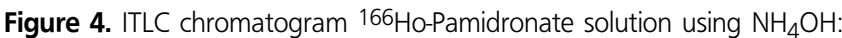
$\mathrm{MeOH}: \mathrm{H}_{2} \mathrm{O}(0.2: 2: 4)$

Table 2. The effect of various molar ratios of $\mathrm{Ho}$ and pamidronate on the radiochemical yield (30 $\mathrm{min}$ at $\mathrm{pH}$. 8-9) $(n=3)$

\begin{tabular}{ll}
\hline Radiochemical yield (\%) & Ho: PMD molar ratio \\
\hline $51 \pm 0.4$ & $1: 5$ \\
$54 \pm 0.2$ & $1: 10$ \\
$68 \pm 0.2$ & $1: 15$ \\
$86 \pm 0.8$ & $1: 20$ \\
$93 \pm 0.7$ & $1: 40$ \\
$95 \pm 0.3$ & $1: 50$ \\
\hline
\end{tabular}

PMD: Pamidronate 


\section{Stability Studies and Protein Binding}

Stability test was developed for the complex in the presence of human serum at $37{ }^{\circ} \mathrm{C}$ using ITLC as mentioned above, and all data within $48 \mathrm{~h}$ were above $89 \%$ at all-time intervals (22). It was identified that protein binding using ITLC of the serumradiopharmaceutical mixture was $57 \%$, while $43 \%$ was found in the free form in the circulation. The protein binding for the PMD ligand has been reported in different references as 54\% in the free form (12), however, there was no data on protein binding for metal PMD complexes in the literature.

\section{Hydroxy Apatite Binding Assay}

HA assay demonstrated high capacity binding for $175 \mathrm{Yb}-\mathrm{ALN}$ to hydroxy apatite. More than $90 \%$ binding was

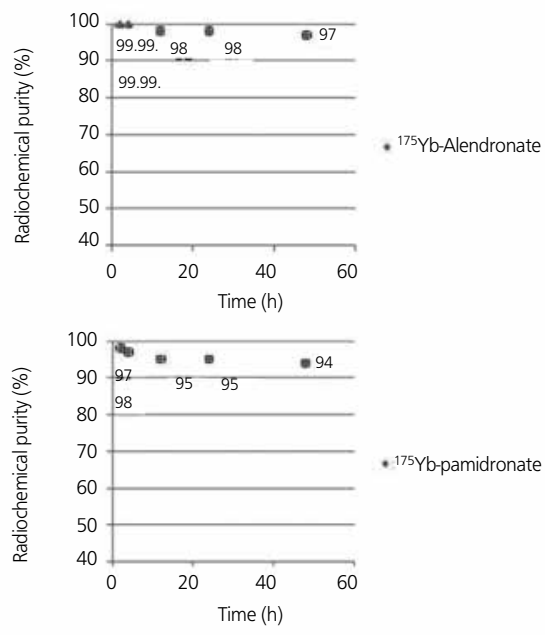

Figure 5. Stability studies for $175 \mathrm{Yb}-$ Alendronate (up) and ${ }^{175} \mathrm{Yb}$ Pamidronate in the final formulation up to $48 \mathrm{~h}$
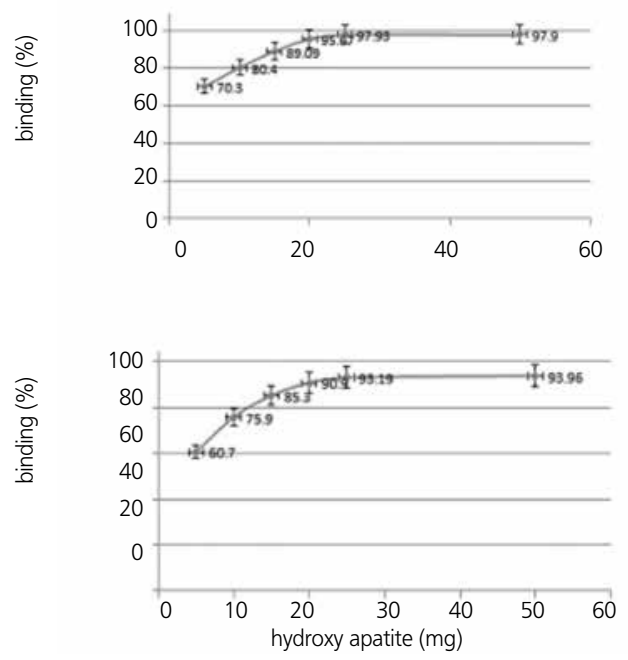

Figure 6. Hydroxy apatite binding assay data for ${ }^{175} \mathrm{Yb}$-Alendronate (up) and ${ }^{175} \mathrm{Yb}$-Pamidronate (down) at $37^{\circ} \mathrm{C}$ in $24 \mathrm{~h}$ observed even at $4 \mathrm{mg}$ of $\mathrm{HA}$, while at $6 \mathrm{mg} \mathrm{HA}$ binding was obtained in $>95 \%$ (Figure 6 ). On the other hand, for $175 \mathrm{Yb}-\mathrm{PAM}$ more than $90 \%$ binding was also observed at $4 \mathrm{mg}$ of $\mathrm{HA}$, while at $6 \mathrm{mg} \mathrm{HA}$ there was $>99 \%$ binding (Figure 7).

\section{Biodistribution}

For better comparison of biodistribution, the study was performed for free $\mathrm{Yb}^{3+}$ as well. The $\% \mathrm{ID} / \mathrm{g}$ data are summarized in Figure 8 . For free $\mathrm{Yb}^{3+}$ cation, the radioactivity was mainly located in the liver, kidney and bone. The free cation is soluble in water and it can be excreted via the urinary tract.

Since the metallic $\mathrm{Yb}^{3+}$ is transferred in the plasma as protein-bond form, the major final accumulation was shown to be in the liver reaching $>3 \%$ after 8 days. Based on bio-equality of lanthanide cations with calcium ions, the $\mathrm{Yb}^{3+}$ is also absorbed on hydroxyl apatite texture of the bone; thus, a $2.25 \%$ bone uptake is observed in 48 hours.

The liver radioactivity uptake of the cation is comparable to other radio-lanthanides such as $\mathrm{Yb}, \mathrm{Sm}$ and $\mathrm{Tb}$ (23).

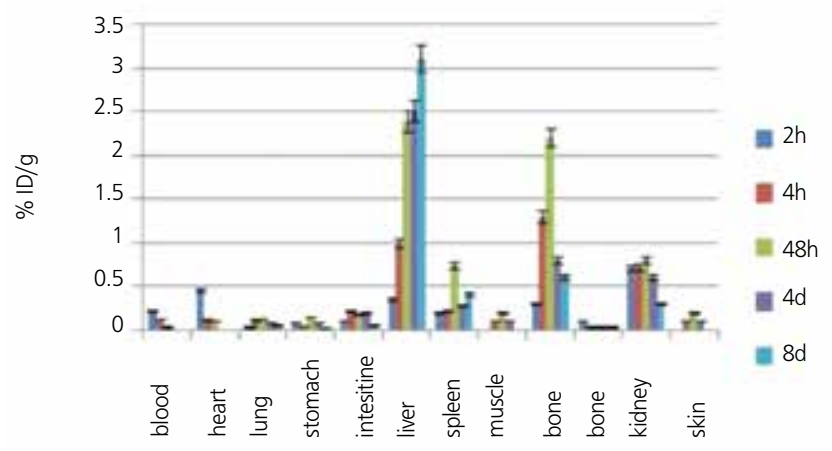

Figure 7. Biodistribution of ${ }^{175} \mathrm{YbCl}_{3}(1.85 \mathrm{MBq}, 50 \mathrm{mCi})$ in wild-type mice $2,4,48 \mathrm{~h}$ and 4,8 days after iv injection via tail vein (ID/g\%: percentage of injected dose per gram of tissue $(n=5)$

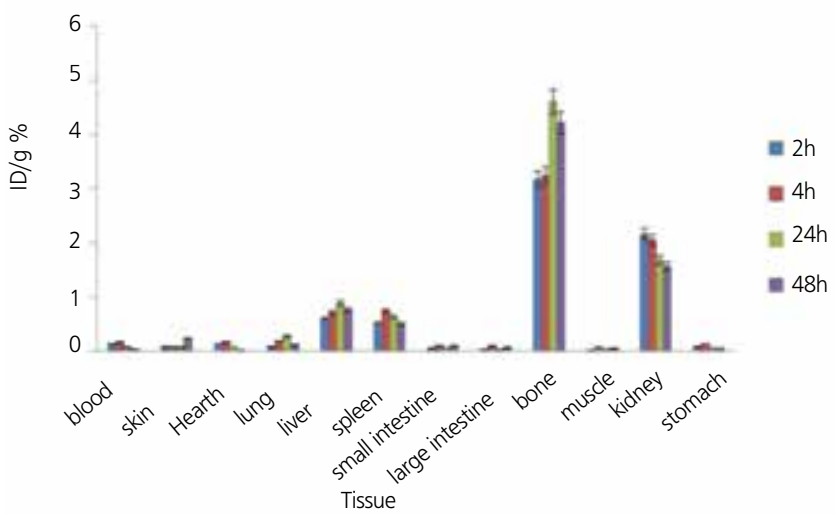

Figure 8. Percentage of injected dose per gram of $175 \mathrm{Yb}$-Pamidronate in wild-type rat tissues at 2, 4, 24 and $48 \mathrm{~h}$ post injection ( $n=3$ ) 
About $2.5 \%$ of the cation radioactivity accumulates in the liver in $48 \mathrm{~h}$. Low blood radioactivity content demonstrates the rapid removal of $175 \mathrm{Yb}$ from the circulation after injection. The lung, muscle and skin do not demonstrate significant ${ }^{175} \mathrm{Yb}$ uptake, in accordance with other cation accumulation patterns. A low bone uptake is observed for $175 \mathrm{Yb}$ that remains almost constant after $48 \mathrm{~h}$ $(0.7 \%)$. Bone uptake of $\mathrm{Yb}-175$ is greater than those of the agents under examination, which is also the case for other radiolanthanides since they accumulate based on Cacation resemblance. However, the major issue in all free lanthanides is the high liver uptake as observed for Sm153 cation or Sm-153 EDTMP. The main issue in bone avid agents is their Bone: liver uptake ratio.

Spleen also has significant $175 \mathrm{Yb}$ uptake possibly related to the reticuloendothelial system. The free cation is soluble in water and it can be excreted via the urinary tract.

The radioactivity biodistribution of $175 \mathrm{Yb}-\mathrm{PMD}(200 \mu \mathrm{Ci}$ in $150 \mu \mathrm{L}$ volume) in rat organs upto $48 \mathrm{~h}$ post-injection was determined, and it was clearly shown that the major portion of the injected $175 \mathrm{Yb}-\mathrm{PMD}$ radioactivity was transferred from the blood circulation into the bones (Figure 8). The significant radioactivity excretion observed in kidneys was anticipated due to the major PMD non-metabolized excretion through the kidneys, that has been already reported (19). As compared to other ${ }^{175} \mathrm{Yb}$ bone seeking agents, i.e. ${ }^{175} \mathrm{Yb}$-DOTMP with less than $3 \%$ bone uptake in $48 \mathrm{~h}$ (24), $175 \mathrm{Yb}$-PAM demonstrated better uptake within the same period. On the other hand, the bone uptake reported for another Yb-175 complex, 175Yb-EDTMP (4.7 at $24 \mathrm{~h}$ ) is very similar to that of $175 \mathrm{Yb}-\mathrm{PAM}(4.6$ at $24 \mathrm{~h})(25)$.

The report denoted that after administration of PMD, $46 \pm 16 \%$ (overall mean $\pm S D$ ) of the parent drug was excreted unchanged in the urine within 120 hours. The cumulative urinary excretion showed linear correlation with dose. The mean \pm SD elimination half-life was $28 \pm 7$ hours. The mean \pm SD total and renal clearances of pamidronate were $107 \pm 50 \mathrm{~mL} / \mathrm{min}$ and $49 \pm 28 \mathrm{~mL} / \mathrm{min}$, respectively. The rate of elimination from bone has not been determined.

It can be suggested that a mild diuretic agent would remove the un-concentrated portion of the radiopharmaceutical into bones from the circulation through urinary tracts, and possibly enhance the bone: non-target ratio for the therapeutic radiopharmaceutical leading to unwanted irradiation doses to the patients (esp. gonads). The liver does not play a significant role in metabolism $(<1 \%)$, and also lower GI (intestines, colon) uptake is observed.

175Yb-ALN also demonstrates significant bone uptake at all-time intervals, especially $24 \mathrm{~h}$ after injection while high kidney uptake is observed at all-time intervals that could be due to urinary excretion of the complex. Urinary excretion rate of $175 \mathrm{Yb}-\mathrm{ALN}$ was higher as compared to ${ }^{175} \mathrm{Yb}$-PAM that has a slightly higher liver uptake. Similarly, the use of a diuretic could reduce the absorbed dose form the kidney to vital organs (Figure 9).
The target: non-target ratio of $175 \mathrm{Yb}-\mathrm{PMD}$ was determined in order to demonstrate the targeting property of radiopharmaceutical 2-48 $\mathrm{h}$ post injection as shown in Table 3. As shown in the table, best targeting can be observed $48 \mathrm{~h}$ post injection (almost half a physical halflife) in the blood, kidney and liver. Interestingly, the same trend has been observed for Ho-166 analogue of this phosphonate (26).

Also in case of $175 \mathrm{Yb}-\mathrm{ALN}$ as shown in the Table 4, the best targeting can be observed in the blood, kidney and liver $48 \mathrm{~h}$ post injection (almost half a physical half-life). However, the biological affinity of this complex into bones is significantly less than the pamidronate analog. Figure 10 demonstrates the non-decay corrected clearance curves from each rat organ after i.v. injection of $175 \mathrm{Yb}-\mathrm{PAM}$ and 175 Yb-ALN.

\section{Dosimetry}

As represented in Table 4, i.v. injection of $175 \mathrm{Yb}-\mathrm{PAM}$ into humans would result in an estimated absorbed dose of

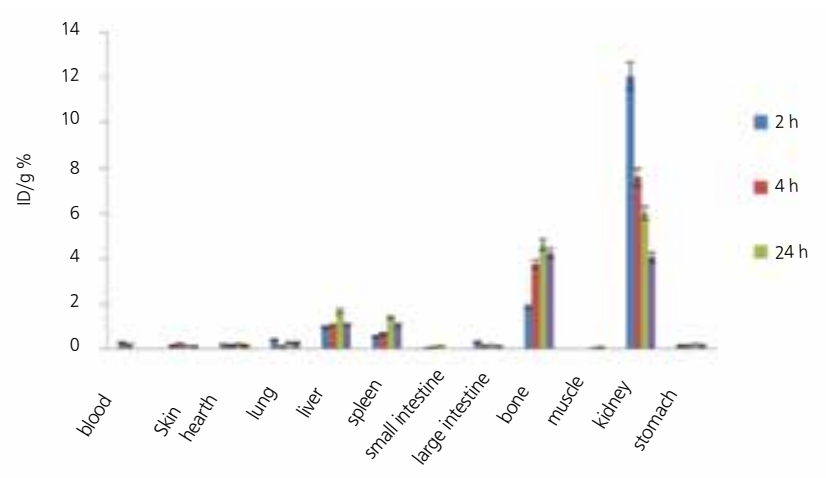

Figure 9. Percentage of injected dose per gram of ${ }^{175} \mathrm{Yb}$-Alendronate in wild-type rat tissues at 2, 4, 24 and 48 h post injection ( $n=3)$

Table 3. Target (bone)/non target ratios for ${ }^{175} \mathrm{Yb}$ Pamidronate at various time intervals in rats organs

\begin{tabular}{lllll}
\hline $\mathbf{4 8} \mathbf{h}$ & $\mathbf{2 4} \mathbf{h}$ & $\mathbf{4} \mathbf{h}$ & $\mathbf{2} \mathbf{h}$ & Organ ratios \\
\hline 2.69 & 2.73 & 1.58 & 1.47 & bone: kidney \\
5.58 & 5.19 & 4.54 & 5.26 & bone: liver \\
120.76 & 79.01 & 20.37 & 24.26 & bone: blood
\end{tabular}

Table 4. Target (bone)/non target ratios for ${ }^{175} \mathrm{Yb}$ Alendronate at various time intervals in rats organs

\begin{tabular}{lllll}
\hline $\mathbf{4 8} \mathbf{h}$ & $\mathbf{2 4} \mathbf{h}$ & $\mathbf{4} \mathbf{h}$ & $\mathbf{2} \mathbf{h}$ & Organ ratios \\
\hline 1.04 & 0.76 & 0.50 & 0.16 & bone: kidney \\
3.91 & 2.79 & 3.60 & 1.93 & bone: liver \\
201.01 & 146.58 & 17.26 & 6.90 & bone: blood
\end{tabular}


$19.9 \mu \mathrm{Sv} / \mathrm{MBq}$ according to prediction based on rat data. While the highest effective absorbed dose for $175 \mathrm{Yb}$-PAM were in the osteogenic cells and kidneys $(26.9 \mu \mathrm{Sv} / \mathrm{MBq})$, other organs receiving high doses were the spleen (20.2 $\mu \mathrm{Sv} / \mathrm{MBq})$, red marrow $(7.9 \mu \mathrm{Sv} / \mathrm{MBq})$ and the heart wall $(6.8 \mu \mathrm{Sv} / \mathrm{MBq})$ in decreasing order. On the other hand, due to the deference in cumulative activity in the kidneys, our estimation shows that i.v. injection of $175 \mathrm{Yb}-\mathrm{ALN}$ into the humans would result in an estimated absorbed dose of $28 \mu \mathrm{Sv} / \mathrm{MBq}$. The highest effective absorbed dose for $175 \mathrm{Yb}-\mathrm{PAM}$ were detected in the kidneys $(84.5 \mu \mathrm{Sv} / \mathrm{MBq})$ followed by the spleen (38.7 $\mu \mathrm{Sv} / \mathrm{MBq})$, osteogenic cells $(27.6 \mu \mathrm{Sv} / \mathrm{MBq})$ and the heart wall $(8.5 \mu \mathrm{Sv} / \mathrm{MBq})$.

Discovering a new radiopharmaceutical agent requires assessment of its biodistribution in nonhuman models prior to its clinical application, most commonly rats, based on the assumption that biodistribution will be similar in rats and in man (27), which is a common first step consistent with the recommendations of ICRP 103 (28).

Although we did not measure the rat's whole body activity at each time point, the prediction can be accepted as precise and close to practical absorbed dose values since activities of more than 11 organs were used in this study. There is another limitation for using the methods described above: the issue in selecting the time points. It would have been better to have more time points before 2 hour to avoid underestimation. Therefore, further studies are required to assess the exact value of cumulative activity in the bladder; however, due to the same kinetics of both radiotracers, it is not expected that results would significantly differ.

The prediction of human dose based on rodent's data is not as simple as we explained, and using extrapolation from

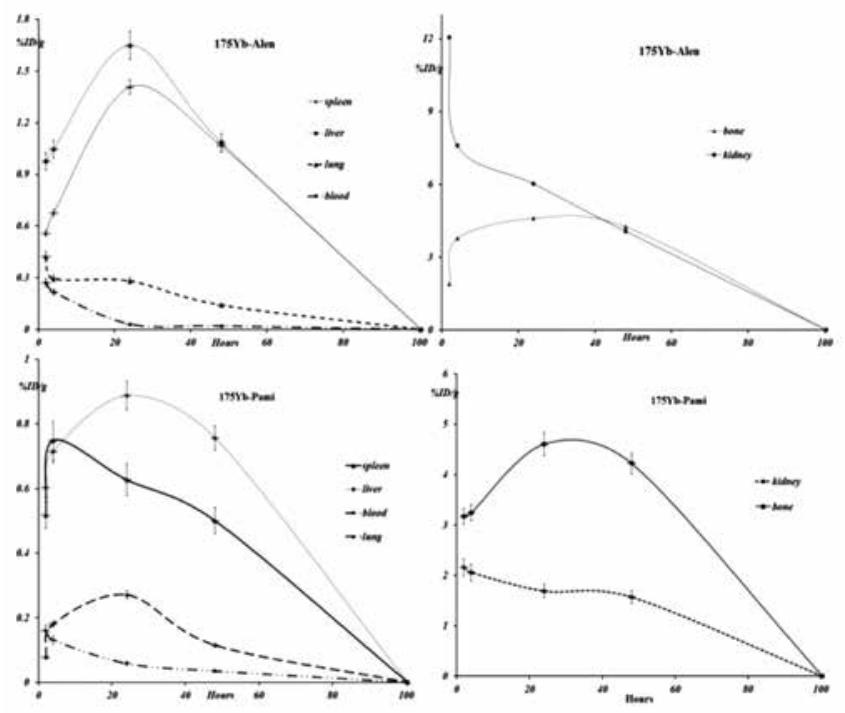

Figure 10. The non-decay corrected clearance curves from each rat organ. The $x$-axis is displayed as hours. Data are presented as mean \pm SD and the mean values as the percentage of administered activity per gram $(\% \mathrm{ID} / \mathrm{g})$ animal data may lead to some over or under estimations. Allowable doses based on human data were somewhat different from those obtained from studies of rodents as well as nonhuman primates Table 5 and Figure 10 compare the increments in human absorbed dose after injection of 175 Yb-PAM versus 175 Yb-ALN $(29,30)$. As indicated in Table 4 , the total body dose for $175 \mathrm{Yb}-\mathrm{ALN}$ was $40 \%$ higher as compared to $175 \mathrm{Yb}-\mathrm{PAM}$. Moreover the received kidney dose was 3 times higher; implicating that $175 \mathrm{Yb}-\mathrm{PAM}$ is more suitable and safer than ${ }^{175} \mathrm{Yb}-\mathrm{ALN}$.

\section{Conclusion}

175Yb-PMD and 175Yb-ALN were prepared (radiochemical purity $>95 \%$ ) using optimization studies. $175 \mathrm{Yb}-\mathrm{PMD}, 175 \mathrm{Yb}-\mathrm{ALN}$ and $166 \mathrm{HoCl}_{3}$ preparations were administered intravenously through the tail vein to rats and biodistribution data was checked $2 \mathrm{~h}$ to $48 \mathrm{~h}$ later, showing at least $72 \%$ accumulation of $175 \mathrm{Yb}-\mathrm{PMD}$ in bony tissues. Satisfactory stability was obtained in the presence of human serum and final formulations. HA binding assay demonstrated $>95 \%$ binding with $4-6 \mathrm{mg}$ of $\mathrm{HA}$ in $24 \mathrm{~h}$ at $37{ }^{\circ} \mathrm{C}$. The complex protein binding was about $50-55 \%$. The high bone uptake ratios at all time intervals for $175 \mathrm{Yb}$ PMD was in accordance with the HA test. The bone uptake ratios at all time intervals were obtained. The bone: kidney, bone: blood and bone: liver uptake ratios were significantly higher for $175 \mathrm{Yb}-\mathrm{PMD}$ at $48 \mathrm{~h}$ post injection $(2.69,5.58$ and 120 respectively). $175 \mathrm{Yb}-\mathrm{PAM}$ demonstrated better uptake at the same time interval as compared to $175 \mathrm{Yb}$ DOTMP ( $<3 \%$ bone uptake in $48 \mathrm{~h})$. On the other hand, the bone uptake reported for $175 \mathrm{Yb}-\operatorname{EDTMP}(4.7$ at $24 \mathrm{~h}$ )

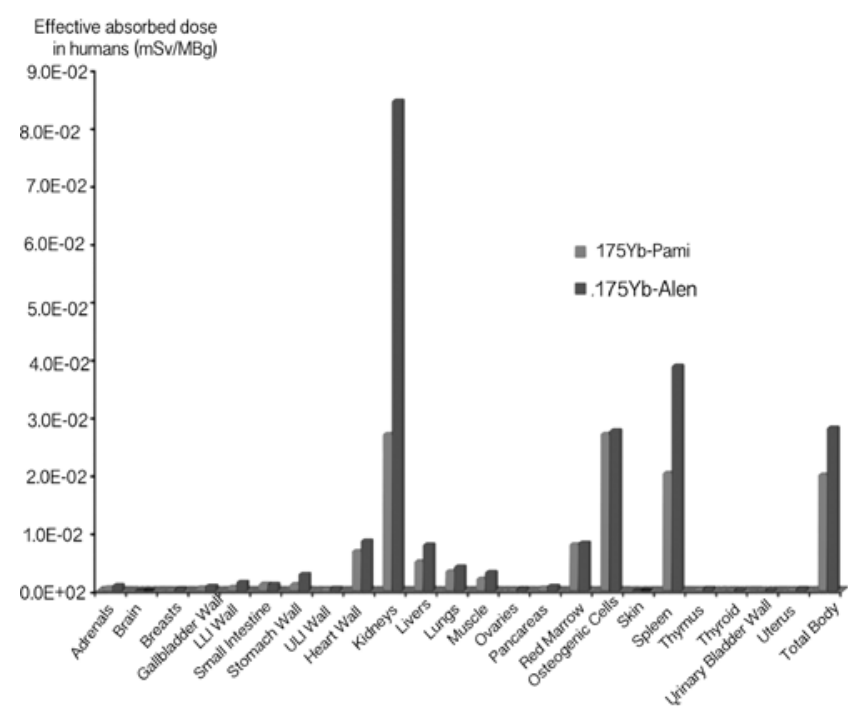

Figure 11. Comparison of effective absorbed dose prediction in humans based on rat data after i.v. injection of ${ }^{175} \mathrm{Yb}$-Pamidronate and ${ }^{175} \mathrm{Yb}$ Alendronate 
Table 5. Prediction of human absorbed dose based on rat data after i.v. administration of $175 \mathrm{Yb}$-Pamidronate and $175 \mathrm{Yb}$ Alendronate

\begin{tabular}{|c|c|c|c|c|}
\hline \multicolumn{2}{|c|}{ 175Yb-ALN } & \multicolumn{2}{|c|}{ 175Yb-PAM } & \multirow[b]{2}{*}{ Target organs } \\
\hline $\begin{array}{l}\text { Effective dose in } \\
\text { humans (mSv/MBq) }\end{array}$ & $\begin{array}{l}\text { Equivalent dose in } \\
\text { humans }(\mathrm{mSv} / \mathrm{MBq})\end{array}$ & $\begin{array}{l}\text { Effective dose in humans } \\
\text { (mSv/MBq) }\end{array}$ & $\begin{array}{l}\text { Equivalent dose in } \\
\text { humans }(\mathrm{mSv} / \mathrm{MBq})\end{array}$ & \\
\hline $8.56 \mathrm{E}-04$ & 7.13E-03 & 4.87E-04 & 4.06E-03 & Adrenals \\
\hline $1.20 \mathrm{E}-05$ & $1.20 \mathrm{E}-03$ & $1.13 \mathrm{E}-05$ & $1.13 \mathrm{E}-03$ & Brain \\
\hline $1.68 \mathrm{E}-04$ & 1.40E-03 & $1.24 \mathrm{E}-04$ & $1.03 \mathrm{E}-03$ & Breasts \\
\hline $7.66 \mathrm{E}-04$ & $6.38 \mathrm{E}-03$ & $4.59 \mathrm{E}-04$ & $3.83 \mathrm{E}-03$ & Gallbladder wall \\
\hline $1.44 \mathrm{E}-03$ & $1.20 \mathrm{E}-02$ & $5.73 E-04$ & 4.77E-03 & LLI wall \\
\hline $1.05 \mathrm{E}-03$ & $8.77 \mathrm{E}-03$ & 1.09E-03 & $9.05 E-03$ & Small intestine \\
\hline $2.80 \mathrm{E}-03$ & $2.34 \mathrm{E}-02$ & $1.04 \mathrm{E}-03$ & $8.69 \mathrm{E}-03$ & Stomach wall \\
\hline 3.55E-04 & $2.96 \mathrm{E}-03$ & $2.22 \mathrm{E}-04$ & $1.85 \mathrm{E}-03$ & ULI wall \\
\hline $8.54 \mathrm{E}-03$ & $7.12 \mathrm{E}-02$ & $6.76 \mathrm{E}-03$ & $5.63 \mathrm{E}-02$ & Heart wall \\
\hline $8.45 \mathrm{E}-02$ & $7.04 \mathrm{E}-01$ & $2.70 \mathrm{E}-02$ & $2.25 \mathrm{E}-01$ & Kidneys \\
\hline $7.86 \mathrm{E}-03$ & $1.96 \mathrm{E}-01$ & $4.95 \mathrm{E}-03$ & $1.24 \mathrm{E}-01$ & Liver \\
\hline 4.07E-03 & $3.39 \mathrm{E}-02$ & $3.27 \mathrm{E}-03$ & $2.73 \mathrm{E}-02$ & Lungs \\
\hline 3.11E-03 & $2.59 \mathrm{E}-02$ & $1.98 \mathrm{E}-03$ & $1.65 \mathrm{E}-02$ & Muscle \\
\hline $1.78 \mathrm{E}-04$ & $2.23 \mathrm{E}-03$ & $1.23 \mathrm{E}-04$ & $1.54 \mathrm{E}-03$ & Ovaries \\
\hline $7.54 \mathrm{E}-04$ & $6.29 \mathrm{E}-03$ & 4.30E-04 & $3.58 \mathrm{E}-03$ & Pancreas \\
\hline $8.18 \mathrm{E}-03$ & $6.82 \mathrm{E}-02$ & $7.94 \mathrm{E}-03$ & $6.62 \mathrm{E}-02$ & Red marrow \\
\hline $2.76 \mathrm{E}-02$ & $2.30 \mathrm{E}-01$ & $2.70 \mathrm{E}-02$ & $2.25 \mathrm{E}-01$ & Osteogenic cells \\
\hline $1.34 \mathrm{E}-05$ & $1.34 \mathrm{E}-03$ & $9.83 \mathrm{E}-06$ & $9.83 \mathrm{E}-04$ & Skin \\
\hline 3.87E-02 & $3.23 \mathrm{E}-01$ & $2.02 \mathrm{E}-02$ & 1.69E-01 & Spleen \\
\hline $2.71 \mathrm{E}-04$ & $2.26 \mathrm{E}-03$ & $2.11 \mathrm{E}-04$ & $1.75 \mathrm{E}-03$ & Thymus \\
\hline $6.02 \mathrm{E}-05$ & 1.50E-03 & $4.78 \mathrm{E}-05$ & $1.20 \mathrm{E}-03$ & Thyroid \\
\hline $6.35 \mathrm{E}-05$ & $1.59 \mathrm{E}-03$ & 4.41E-05 & $1.10 \mathrm{E}-03$ & Urinary bladder wall \\
\hline $2.37 \mathrm{E}-04$ & $1.97 \mathrm{E}-03$ & $1.63 \mathrm{E}-04$ & $1.36 \mathrm{E}-03$ & Uterus \\
\hline $2.80 \mathrm{E}-02$ & $2.80 \mathrm{E}-02$ & 1.99E-02 & 1.99E-02 & Total body \\
\hline
\end{tabular}

LLI: Lower large intestine, ULI: Upper large intestine, ALN: Alendronate, PAM: Pamidronate

is very similar to that of 175 Yb-PAM (4.6 at $24 \mathrm{~h}$ ). Based on calculations, the total body dose for $175 \mathrm{Yb}-\mathrm{ALN}$ is $40 \%$ higher as compared to 175Yb-PAM (especially kidneys) indicating that $175 \mathrm{Yb}-\mathrm{PAM}$ is a possible safer agent than $175 Y$ Yb-ALN.

Ethics Committee Approval: An approval was obtained from the Nuclear Science and Technology Research Institute Ethics Committee to conduct this research study, Informed Consent: It was taken, Concept: Amir R Jalilian, Design: Amir R Jalilian, Ali Bahrami-
Samani, Data Collection or Processing: Ashraf Fakhari, Hassan Yousefnia, Mehdi Shafiee-Ardestani, Analysis or Interpretation: Saeed Shanehsazzadeh, Amir R Jalilian, Fariba Johari-Daha, Literature Search: Ashraf Fakhari, Mehdi Shafiee-Ardestani, Writing: Ashraf Fakhari, Amir R Jalilian, Ali Khalaj, Peer-review: External and internal peer-reviewed, Conflict of Interest: No conflict of interest was declared by the authors, Financial Disclosure: The work was performed by the financial support of Deputy of Research, Tehran University of Medical Sciences. 


\section{References}

1. Serafini AN. Therapy of metastatic bone pain. J Nucl Med 2001;42:895-906.

2. Eary JF, Collins C, Stabin M, Vernon C, Petersdorf S, Baker M, Hartnett S, Ferency S, Addison SJ, Appelbaum F. Smarium-153EDTMP biodistribution and dosimetry estimation. J Nucl Med 1993;34:1031-1036.

3. Breitz HB, Wendt RE 3rd, Stabin MS, Shen S, Erwin WD, Rajendran JG, Eary JF, Durack L, Delpassand E, Martin W, Meredith RF. 166Ho-DOTMP radiation-absorbed dose estimation for skeletal targeted radiotherapy. J Nucl Med 2006;47:534-542.

4. Chakraborty S, Unni PR, Venkatesh M, Pillai MR. Feasibility study for production of $175 \mathrm{Yb}$ : a promising therapeutic radionuclide. Appl Radiat Isot 2002;57:295-301.

5. Firestone RB, Chu S, Baglin CM. of the Table of Isotopes: 1998 Update. In: editor. editors.: 1997.

6. Nikzad $M$, Jalilian AR, Shirvani-Arani S, Bahrami-Samani A, Golchoubian H. Production, quality control and pharmacokinetic studies of 177Lu-zoledronate for bone pain palliation therapy. J Radioanal Nucl Chem 2013;298:1273-1281.

7. Shanehsazzadeh S, Lahooti A, Sadeghi HR, Jalilian AR. Estimation of human effective absorbed dose of $67 \mathrm{Ga}-\mathrm{Cd}$ tpa-gonadorelin based on biodistribution rat data. Nucl Med Commun 2011;32:37-43.

8. Shanehsazzadeh S, Yousefnia H, Lahooti A, Zolghadri S, Jalilian $A R$, Afarideh $H$. Assessment of human effective absorbed dose of $67 \mathrm{Ga}-\mathrm{ECC}$ based on biodistribution rat data. Ann Nucl Med 2015:29:118-124

9. Lahooti A, Shanehsazzadeh S, Jalilian AR, Tavakoli MB. Assessment of effective absorbed dose of (111)In-DTPA-Buserelin in human on the basis of biodistribution rat data. Radiat Prot Dosimetry 2013;154:1-8.

10. cGRPP-guidelines, version 2 March 2007, EANM Radiopharmacy Committee, Guidelines On Current Good Radiopharmacy, Practice (CGRPP) in the Preparation of Radiopharmaceuticals.

11. Dar UK, Khan IU, Javed M, Ahmad F, Ali M, Hyder SW. Preparation and biodistribution in mice of a new radiopharmaceutical technetium-99m labeled methotrexate. as a tumor diagnostic agent. Hell J Nucl Med 2012;15:120-124.

12. Neves M, Gano L, Pereira N, Costa MC, Costa MR, Chandia M, Rosado M, Fausto R. Synthesis, characterization and biodistribution of bisphosphonates Sm-153 complexes: correlation with molecular modeling interaction studies. Nucl Med Biol 2002;29:329-338.

13. Jalilian A, Shanehsazzadeh S, Akhlaghi M, Garoosi J, Rajabifar S, Tavakoli M. Preparation and evaluation of [Ga-67]-DTPA- $\beta-1-24$ corticotrophin in normal rats. Radiochimica Acta 2008;96:435439.

14. Jalilian $A R$, Shanesazzadeh $S$, Rowshanfarzad $P$, Bolourinovin $F$, Majdabadi A. Biodistribution study of [61-Cu] pyruvaldehyde-bis (N-4-methylthiosemicarbazone) in normal rats as a PET tracer. Nuclear Science and Techniques 2008;19:159-164.

15. Jalilian AR, Sardari D, Kia L, Rowshanfarzad P, Garousi J, Akhlaghi M, Shannehsazzadeh S, Mırzall M. Preparation, quality control and biodistribution studies of two [111/n]-rituximab immunoconjugates. Sci Pharm 2008;76:151-170.

16. Moghaddam AK, Jalilian AR, Hayati $V$, Shanehsazzadeh $S$, Dodangeh A, editors. Evaluation And Calculation of
Human absorbed dose of 201TI (III)-DTPA-HIgG based on biodistribution data in rats. Journal of Labelled Compounds \& Radiopharmaceuticals; 2011: Wiley-Blackwell Commerce Place, 350 Main St, Malden 02148, MA USA.

17. Khorrami Moghaddam A, Reza Jalilian A, Hayati V, Shanehsazzadeh S. Determination of human absorbed dose of 201TI(III)-DTPA-HIgG based on biodistribution data in rats. Radiat Prot Dosimetry 2010;141:269-274.

18. Shanehsazzadeh $S$, Jalilian $A R$, Sadeghi $H R$, Allahverdi $M$. Determination of human absorbed dose of 67GA-DTPA-ACTH based on distribution data in rats. Radiat Prot Dosimetry 2009:134:79-86

19. Sparks RB, Aydogan B. Comparison of the effectiveness of some common animal data scaling techniques in estimating human radiation dose. Sixth International Radiopharmaceutical Dosimetry Symposium Oak Ridge; Oak Ridge Associated Universities 1996. p. 705-16.

20. Snyder W, Ford M, Warner G, Watson S. S" absorbed dose per unit cumulated activity for selected radionuclides and organs. MIRD Pamphlet No. 11. Society of Nuclear Medicine, New York, 1975.

21. ICRP. Radiation dose to patients from radiopharmaceuticals. Addendum 3 to ICRP Publication 53. ICRP Publication 106. Approved by the Commission in October 2007. Ann ICRP 2008;38:1-197.

22. Vahidfar N, Jalilian AR, Fazaeli Y, Bahrami-Samani A, Beiki D, Khalaj D. Radiosynthesis and biological evaluation of $166 \mathrm{Ho}$ labeled methoxylated porphyrins as possible therapeutic agents. J Radioanal Nucl Chem 2014:301:269-276.

23. Du XL, Zhang TL, Yuan L, Zhao YY, Li RC, Wang K, Yan SC, Zhang L, Sun H, Qian ZM. Complexation of ytterbium to human transferrin and its uptake by K562 cells. Eur J Biochem 2002;269:6082-6090.

24. Safarzadeh L, Ghannadi-Maragheh M, Anvari A, Aghamiri SMR, Shirvani-Arani S, Bahrami-Samani A. Production, radiolabeling and biodistribution studies of $175 \mathrm{Yb}-\mathrm{DOTMP}$ as bone pain palliation. Iran J Pharmaceut Sci 2012;8:135-141.

25. Mathew B, Chakraborty S, Das T, Sarma HD, Banerjee S, Samuel G, Venkatesh M, Pillai MR. 175Yb labeled polyaminophosphonates as potential agents for bone pain palliation. Appl Radiat Isot 2004; 60:635-642.

26. Fakhari $A$, Jalilian $A R$, Yousefnia $H$, Johari-Daha $F$, Mazidi $M$, Khalaj A. Development of 166Ho-pamidronate for bone pain palliation therapy. J Radioanal Nucl Chem 2015;303:743-750.

27. Sadeghzadeh M, Shanehsazzadeh S, Lahooti A. Assessment of the effective absorbed dose of 4-benzyl-1-(3-[125I]iodobenzylsulfonyl) piperidine in humans on the basis of biodistribution data of rats. Nucl Med Commun 2015;36:90-94.

28. No authors listed. The 2007 Recommendations of the International Commission on Radiological Protection. ICRP publication 103. Ann ICRP 2007;37:1-332.

29. Lu JQ, Ichise M, Liow JS, Ghose S, Vines D, Innis RB. Biodistribution and radiation dosimetry of the serotonin transporter ligand 11C-DASB determined from human whole-body PET. J Nucl Med 2004:45:1555-1559.

30. Wilson AA, Ginovart N, Hussey D, Meyer J, Houle S. In vitro and in vivo characterisation of [11C]-DASB: a probe for in vivo measurements of the serotonin transporter by positron emission tomography. Nuclear Med Biol 2002;29:509-515. 